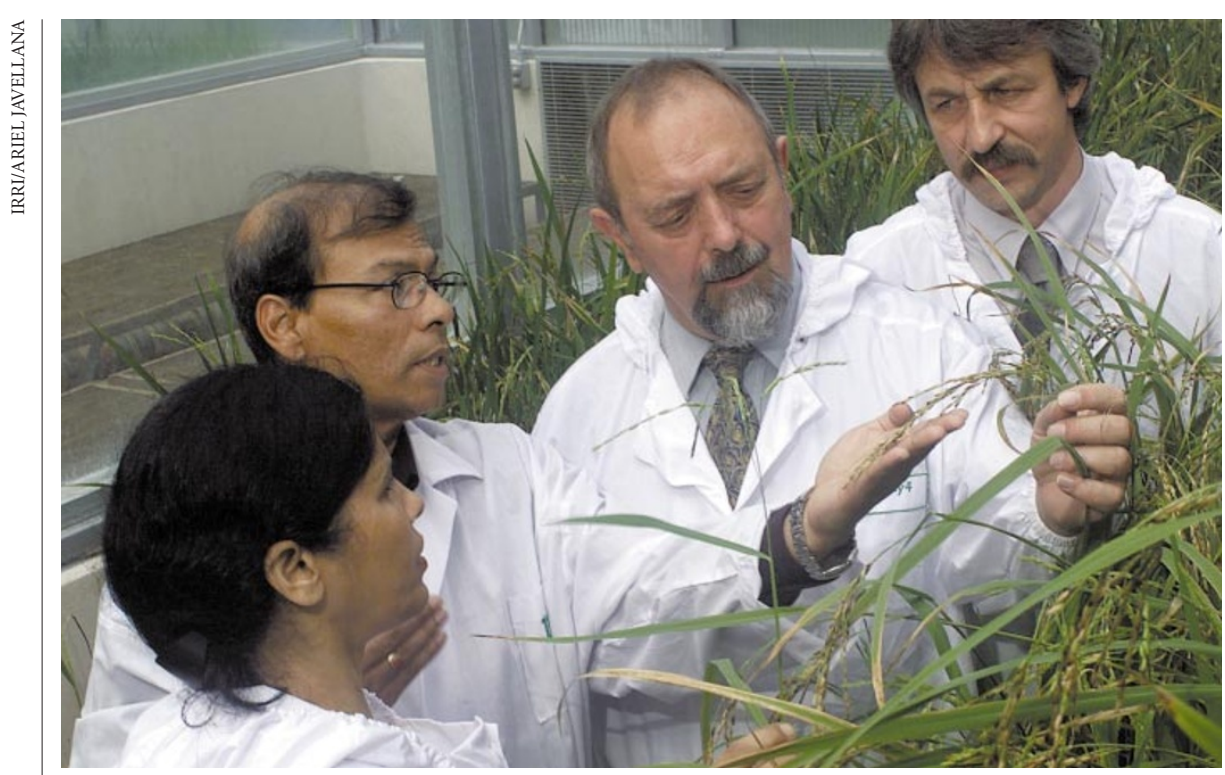

Golden future: from right, Peter Beyer, Ingo Potrykus and colleagues with the rice that they developed.

\title{
Designer rice to combat diet deficiencies makes its debut
}

\section{Quirin Schiermeier, Munich}

Heralding the launch of the humanitarian 'Golden Rice' project, the first free samples of this new type of rice - genetically engineered to contain vitamin A precursors were last week shipped to the International Rice Research Institute (IRRI) in Los Baños, Philippines.

This is the first of many planned deliveries of the rice to non-commercial research institutes in China, India, Africa and Latin America. The institutes will conduct biosafety studies, and then use traditional breeding techniques to confer the beneficial traits of the transgenic rice to strains adapted to local growing conditions.

Thanks to a unique arrangement between the two inventors of Golden Rice and the agribusiness Syngenta, to which the inventors assigned all commercial rights, subsistence farmers in any developing country can cultivate Golden Rice varieties, once available, licence-free. Subsistence farmers are defined as having annual earnings below $\$ 10,000$ per year.

The inventors are plant scientist Ingo Potrykus, who retired from the Swiss Federal Institute of Technology in Zurich in 1999, and biochemist Peter Beyer of the University of Freiburg in Germany.

The Golden Rice project was promoted by Potrykus, who wanted his research to help combat the vitamin A deficiencies prevalent in many poor countries, particularly those relying on rice as a major food source. Rice plants do not normally produce carotenoids, vitamin A precursors, in the grain. A 'humanitarian board' made up of the two inventors and representatives of the Rockefeller Foundation, the World Health Organization and the biotechnology industry, will oversee the distribution of the rice to the research institutes.

Syngenta - the world's largest agribusiness, which this week announced the completion of the entire rice genome (see right) - and several other companies holding patents relating to different steps in the development of Golden Rice, have agreed to waive licence fees for the project. "This was very complicated to arrange, because we had used 70 patents from 32 companies and universities," says Potrykus.

Nor was it straightforward for Potrykus and his colleagues to donate their own intellectual property rights. They initially found it hard to convince the European Commission, which funded some of the work, that donating licences for humanitarian purposes would not interfere with the commission's requirement that its research should strengthen the competitiveness of European industry. But eventually the commission welcomed the Golden Rice achievement.

Others are more cynical about Golden Rice, seeing it as a means for the plant biotechnology industry to polish its tarnished image. Environmental groups such as Greenpeace have called the project a Trojan horse, saying it opens the door to extended cultivation of genetically modified crops in the developing world.

"This is not true," says Potrykus. "We are making sure that varieties important to the poor will be used, not fashionable varieties for the urban middle class."
Commercial sector scores success with whole rice genome

\section{David Dickson, London}

and David Cyranoski, Tokyo

Syngenta, the world's largest agribusiness corporation, and gene-discovery company Myriad Genetics have sequenced the complete rice genome. But the sequence will be available only through contracts and will not be published.

The genome is the second largest to have been sequenced to date (smaller only than the human genome) and the first for a crop plant. The project took only 18 months and has produced a genome map that the companies say is " $99.5 \%$ complete". The publicly funded effort to sequence the rice genome's 430 million DNA bases, led by Japan, is three years away from completion.

Myriad, which is based in Salt Lake City, says that its proprietary highthroughput sequencing facilities enabled it to complete the genome six months ahead of schedule - earning a \$3 million bonus from Syngenta as part of a $\$ 33$ million deal.

The companies' success has raised worries about the impact on poorer countries that rely on rice as a staple food crop. But Syngenta says it will provide information and technology that can produce crop improvements for subsistence farm-related research "without royalties or technology fees".

The company says that it will make its rice genome data - derived from the Nipponbare variety - available to researchers through "research contracts".

Given the apparent - and apparently unexpected - similarity between the rice genome and those of various cereals, the rice sequence is expected to aid the study of crops such as wheat, corn and barley.

Syngenta's announcement has shaken partners in the publicly funded International Rice Genome Sequencing Project (IRGSP), which has sequenced 5\% of the genome to completion and an additional $25 \%$ to the level of quality achieved by Syngenta's sequence.

Takuji Sasaki, principal investigator of the IRGSP, says the project's partners will meet next week and discuss Syngenta's results. He says the claim of $99.5 \%$ completeness will be difficult to verify "as the company won't show its cards". But he worries that politicians may nonetheless consider the job done and pull the plug on the publicly funded project. This would be unwise, he says, as the IRGSP's sequence will be both more accurate than Syngenta's and freely available. 